\title{
Pilot Survey of a Group of Remote Villages in Masasi District, Tanzania*
}

\author{
BRIAN WHEATLEY \\ Formerly Regional Leprosy Officer, Mtwara Region, Tanzania†
}

\begin{abstract}
This survey revealed that about $40 \%$ of the patients with leprosy in the area were not coming forward for treatment.
\end{abstract}

The treatment of patients with leprosy has been carried out in the Masasi District of Southern Tanzania (Fig. 1) for at least 40 years, thanks to the efforts of Mission medical staff and support from the major leprosy associations. As a result of this, and especially due to the work of the present worker from the British Leprosy Relief Association (LEPRA), a very effective Dispensary treatment scheme has been constructed. The designation of the Mission hospital at Mkomaindo as the Masasi District Hospital (in 1965) brought together, under one administration, all the Local Council and Mission Dispensaries, and thus centralized the control of leprosy work throughout the whole district. The treatment scheme now consists of 24 dispensaries in an area of $6000 \mathrm{sq}$. miles $(15,400$ sq. km.), 3 strategically placed holding units each with a few beds for acute or "surgical" cases, and the District Hospital which also has a 10-bedded holding unit for patients with severe reactions or those needing surgical care not treatable elsewhere (Fig. 2).

When the statistics for this scheme were collected it was obvious that even allowing for possible error in the detailed figures, the incidence of leprosy was high. In Masasi District, with a population of 130,000 and 4000 leprosy patients under treatment, the incidence is $3 \%$. At this stage no work, such as school surveys or village surveys, had been done in terms of finding patients. With a well-established treatment scheme this was the obvious next step.

\footnotetext{
*Received for publication 26 Jurie, 1969.

†Present address: 96 Wingrove Road, Newcastle upon Tyne, 4.
}

However, it was felt that in order to plan the direction of future work it was necessary to have at least a rough assessment of the number of undiagnosed cases within the community. A pilot survey was therefore indicated. In parts of the District there had developed over the last few years a gradual drift of the population away from the Rovuma river and towards the main road, largely for economic reasons. This population movement, it was felt, would complicate any survey, and it was therefore decided to perform the pilot survey in a more remote area of the District in which the old village system still operated and where there was little population movement and a fairly good leprosy treatment system already existed. The area selected comprised a group of villages dependent on the Dispensary at Nakopi (see Fig. 2). These villages form an independent group (Fig. 3) with definite boundaries, thus making it possible to keep the survey within circumscribed limits. Also, by using the system of Balozi (10 House Chairmen) it was possible, provided all the Balozi co-operated, to be certain that the whole population had been seen. Thus, the initial step was for 2 members of the survey team to visit each village, call a meeting of the Balozi-whose names had already been obtained from official sources-and explain to them the purpose of the survey. All eventually consented. At the dates and times arranged the survey team returned and over a period of 2 weeks systematically examined the population, inspections being carried out in small grass cubicles which had been constructed by the people themselves. 


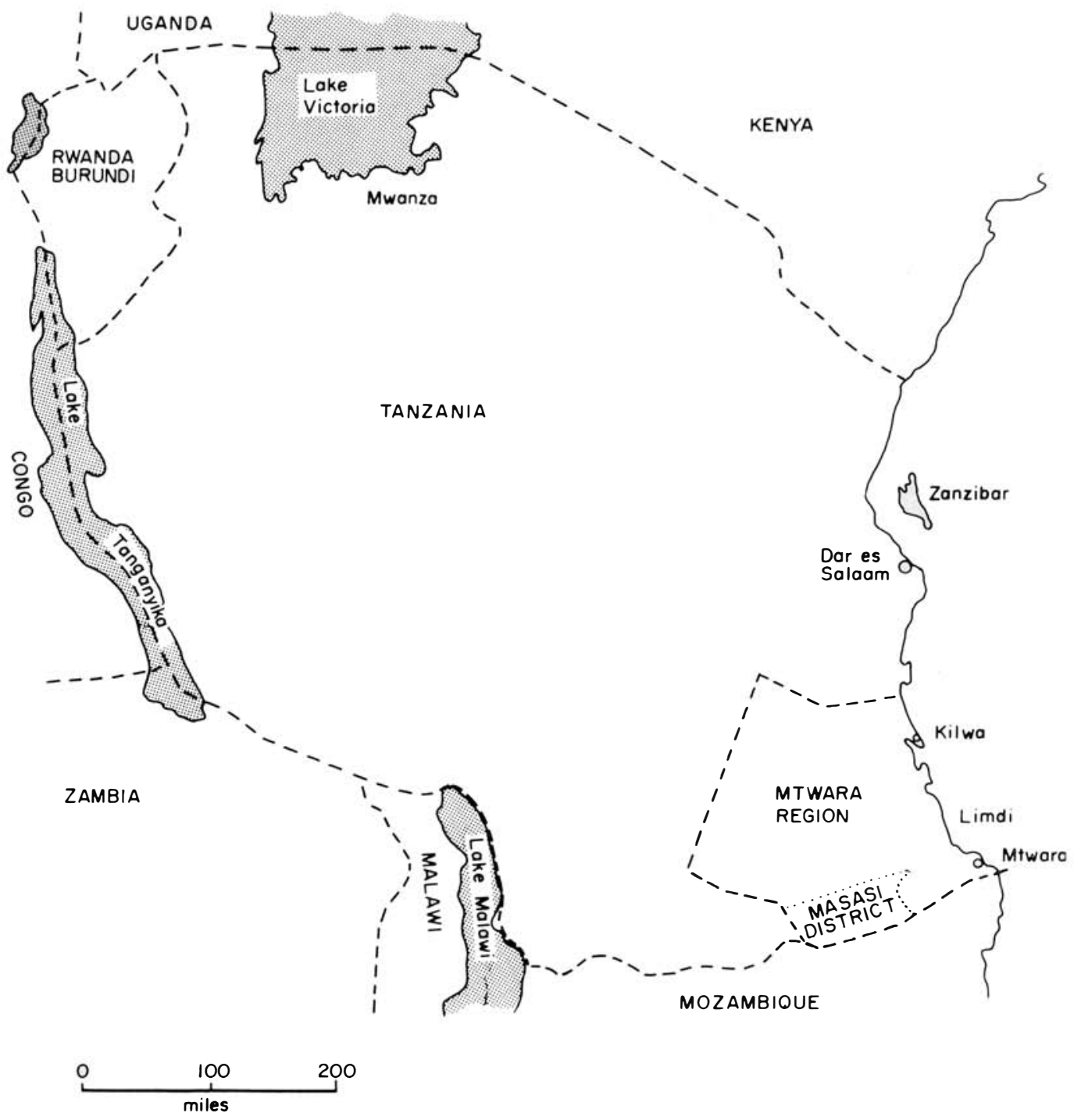

FIG. I

\section{RESULTS}

The findings were noted according to sex, age (adult or child), and type (lepromatous, tuberculoid or indeterminate). Smears were taken in any doubtful cases. The results are shown in Tables 1 and 2.

\section{DISCUSSION}

As expected, most of the cases are on the tuberculoid side of the spectrum; no new lepromatous cases were found. Sex distribution in adults was found to be predominantly male, in contrast with the general tendency to a 


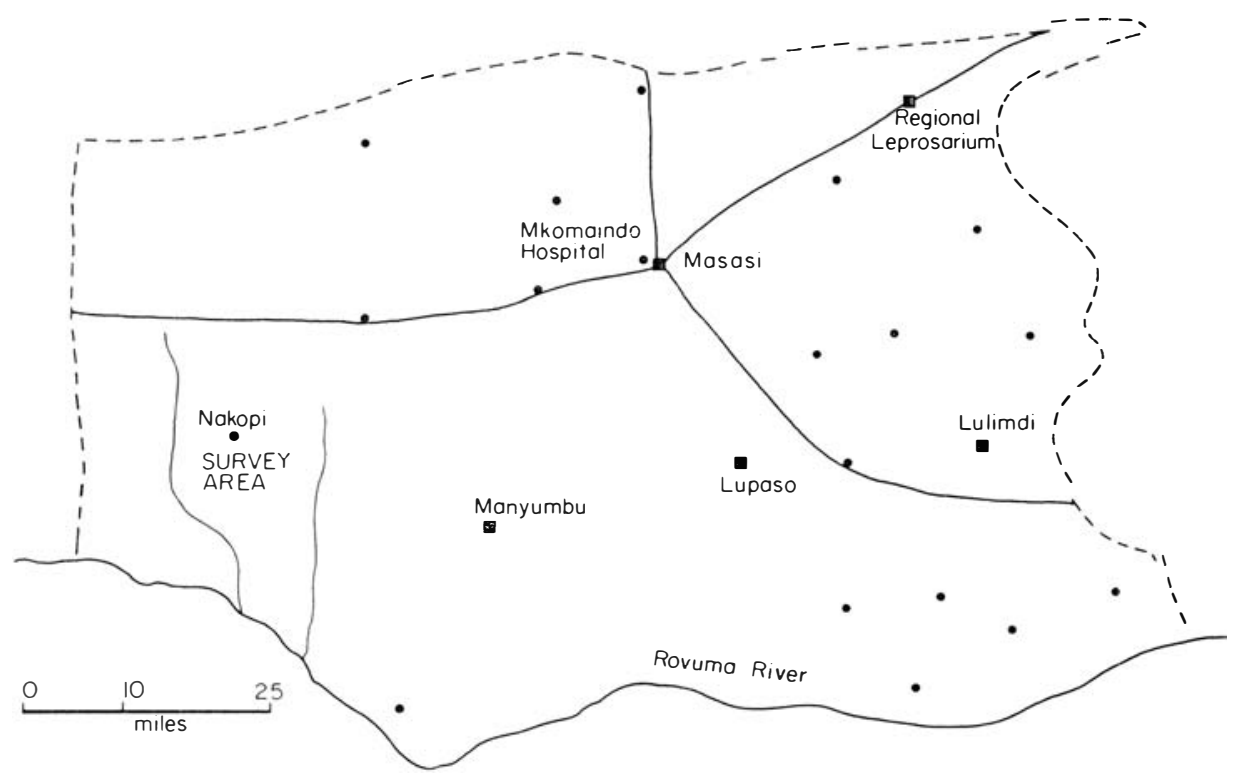

FIG. 2

Masasi district. _, Main roads; $\mathbf{\square}$, main centres with holding units; • dispensaries.
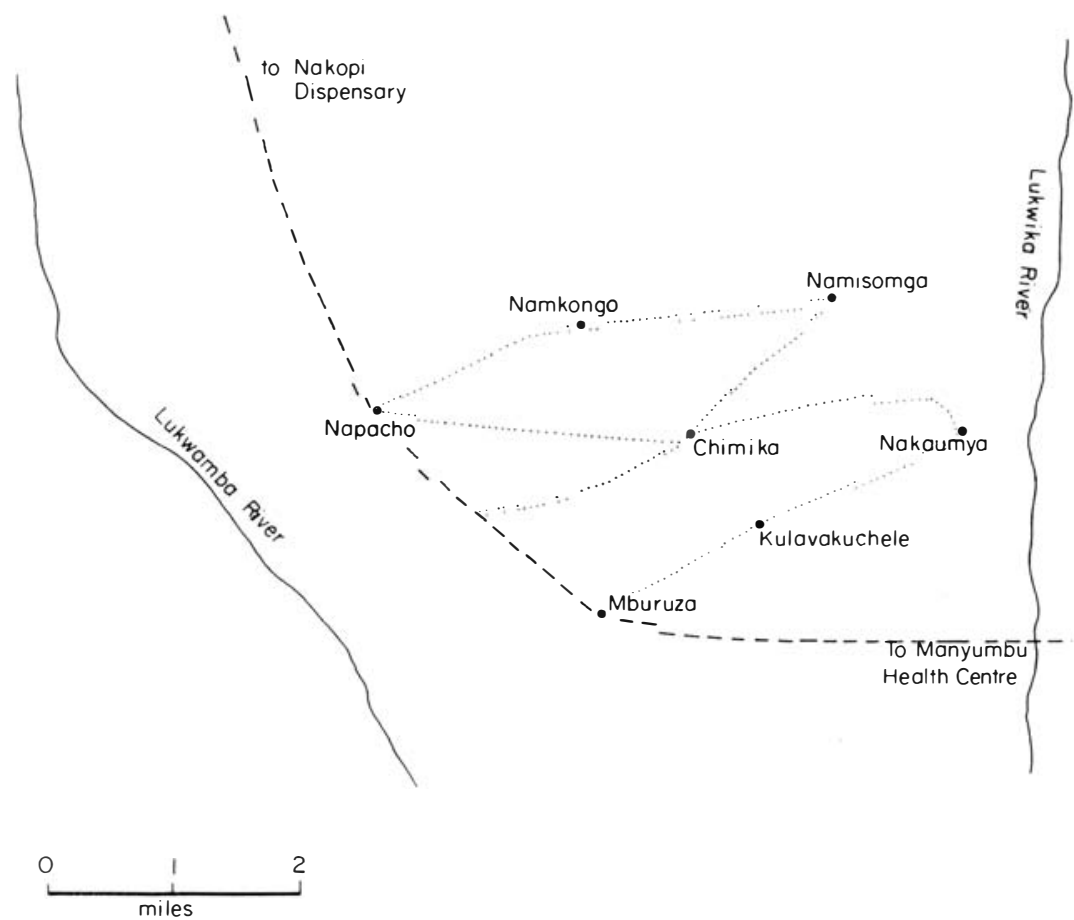

FIG. 3

Survey area. - - -, Track; ....., footpaths. 
TABLE ।

\begin{tabular}{lrccc}
\hline \multicolumn{1}{c}{ Village } & Adults & $\begin{array}{c}\text { Children } \\
\text { (under } \\
\text { 14 years) }\end{array}$ & $\begin{array}{c}\text { Total } \\
\text { examined }\end{array}$ & $\begin{array}{c}\text { Totalnew } \\
\text { cases } \\
\text { found }\end{array}$ \\
\hline Napacho & 73 & 40 & 113 & 2 \\
Mburuza & 120 & 57 & 177 & 1 \\
Namkongo & 39 & 13 & 52 & 2 \\
Chimika & 127 & 59 & 186 & 6 \\
Nakaunya & 60 & 44 & 104 & 3 \\
Namisonga & 40 & 20 & 60 & 0 \\
Kulavakuchele & 49 & 28 & 77 & 3 \\
Total & $5(1)$ & 261 & 769 & 17 \\
\hline
\end{tabular}

TABLE 2

\begin{tabular}{lccccr}
\hline \multicolumn{1}{c}{$\begin{array}{c}\text { Type of } \\
\text { leprosy }\end{array}$} & \multicolumn{2}{c}{ Children } & \multicolumn{2}{c}{ Adults } & Total \\
\hline Male & Female & Male & Female & \\
\hline $\begin{array}{l}\text { Tuberculoid } \\
\text { Indeterminate }\end{array}$ & - & - & 8 & 4 & 12 \\
Lepromatous & - & 4 & - & 1 & 5 \\
Total & - & 4 & 8 & 5 & 17 \\
$\begin{array}{l}\text { Numbers } \\
\quad \text { examined }\end{array}$ & 128 & 133 & 233 & 275 & 769 \\
\hline
\end{tabular}

majority of females among patients under treatment in the district as a whole. This may merely reflect a reluctance on the part of the men to come forward for treatment, but a more extensive survey would be needed to confirm this. There is no obvious reason for the absence of new cases in male children. All the new cases in female children were of indeterminate type, thus differing from the usual slight preponderance of tuberculoid cases among children under treatment. This is possibly because mothers are familiar with the minor tuberculoid lesions but not with those of the indeterminate type and therefore tend not to take the child for treatment until more definitive lesions appear. The finding of 17 new cases in a total examined population of 769 thus gives an incidence of previously undiagnosed leprosy in the community of just over $2 \%$. This compares with a total of 29 patients already under treatment for leprosy in the same community, which gives an incidence of "patients under treatment" of $3 \%$, which is in keeping with the rest of the district. If these figures are taken as typical then, in spite of an extensive leprosy treatment scheme working for many years and being efficiently run, some $40 \%$ of patients with leprosy are not coming forward for treatment. It also shows an overall incidence of $5 \%$ for the district, thus putting the area among the higher endemic areas in Africa.

The survey confirmed the need to carry out a diagnostic search in the villages and schools, despite an apparently effective leprosy treatment scheme already in operation, and it has also demonstrated the size of the problem in this area. Even allowing for the fact that it has proved possible to discharge from the dispensaries about $15 \%$ of patients as clinically cured after 5 years' treatment, if all the potential patients are found and brought for treatment this will produce a considerably increased work load for the already hard-worked clinics. This is, however, a problem which, now that its potential size is known, must be accepted and overcome if the Masasi Leprosy Scheme is to be successful, as also must be the man-power problem for the necessary survey work. As a direct result of the present survey a new visiting point has been established between Napacho and Mburuza (see Fig. 3).

The relatively small numbers involved in this pilot survey could possibly give a slightly false picture. However, initial surveys carried out in schools in the district have also given a figure of about $2 \%$ for previously undiagnosed cases; it would seem therefore that this figure is at least of the right order. It is hoped that the survey may be repeated in about 3 years' time for comparison with the present findings.

\section{ACKNOWLEDGEMENTS}

I would like to express my thanks to Dr. David Gill, District Medical Officer, Masasi, and Mr. Ronald Heald, LEPRA worker, for their invaluable assistance, and also to Mr. Francis Namkuwa and Mr. John Msusa, leprosy workers, for all their efforts in seeing Balozi and examining patients. 